\title{
Note
}

\section{NMR spectroscopy of nystose}

Johan W. Timmermans a , Picter de Waard a, Huibert Tournois a , Bas R. Leeflang ${ }^{\mathrm{b}}$ and Johannes F.G. Vliegenthart ${ }^{\mathrm{b}, *}$

${ }^{a}$ ATO-DLO, P.O. Box 17, 6700 AA Wageningen (Netherlands)

${ }^{b}$ Department of Bio-organic Chemistry, Bijvoet Center, Utrecht University, P.O. Box 80.075, 3508 TB Utrecht (Netherlands)

(Received April 18th, 1992; accepted November 11th, 1992)

Sucrose (1), 1-kestose (2), and nystose (3) are the smallest inulin-related oligosaccharides ${ }^{1,2}$, which consist of $(2 \rightarrow 1)$-linked $\beta$-D-fructofuranosyl residues, terminated by an $\alpha$-D-glucopyranosyl unit in a $(1 \rightarrow 2)$ linkage. Several ${ }^{1} \mathrm{H}$ and ${ }^{13} \mathrm{C}$ NMR assignments and some $J_{\mathrm{H}, \mathrm{H}}$ and $J_{\mathrm{H}, \mathrm{C}}$ values for inulin and inulin-related oligosaccharides have been published ${ }^{3-17}$. Only a partial interpretation of the spectrum of 3 has been reported ${ }^{16}$ and a complete assignment of the ${ }^{1} \mathrm{H}$ NMR spectrum is now presented. For purposes of comparison, NMR data on 1 have been included.

The signal of Glc H-1 of 3 can be identified easily, and the signals for H-2/5 can then be characterised from the 2D DQF-COSY spectrum and the 2D HOHAHA spectrum with a short mixing time (see Experimental). In the 2D HOHAHA spectrum with a long mixing time, cross-peaks can be found between $\mathrm{H}-6 \mathrm{a}, 6 \mathrm{~b}$ and $\mathrm{H}-4$ of $\mathrm{Glc}$, thus completing the assignment of the Glc resonances. In a similar way, the resonances of $\mathrm{H}-3 / 6$ of the Fru units can be identified, making use of the doublet for $\mathrm{H}-3$. The remaining ${ }^{1} \mathrm{H}$ signals are due to the isolated Fru $\mathrm{H}-1 \mathrm{a}, 1 \mathrm{~b}$ spin systems. In the shift-correlation spectra, two coupled doublets for each of those $\mathrm{CH}_{2}$ groups can be found.

The Glc and Fru spin systems are easily distinguishable. However, the individual Fru units could not be distinguished by ${ }^{1} \mathrm{H}$ NMR spectroscopy. The complete ${ }^{1} \mathrm{H}$ assignments were obtained by application of $2 \mathrm{D}$ HMBC spectroscopy. Signals for Fru C-2 can be recognised by their downfield positions. The C-2 resonance at $104.54 \mathrm{ppm}$ has cross-peaks in the 2D HMBC spectrum (Fig. 1) with the Glc H-1 (5.431 ppm) and the Fru H-1a,1b resonances ( 3.741 and $3.840 \mathrm{ppm}$, respectively). Therefore, these $\mathrm{C}-2$ and $\mathrm{H}-1 \mathrm{a}, 1 \mathrm{~b}$ resonances belong to Fru-1 (the Fru residue attached to Glc is designated Fru-1). The Fru C-2 resonance at 104.98 ppm has

\footnotetext{
* Corresponding author.
} 

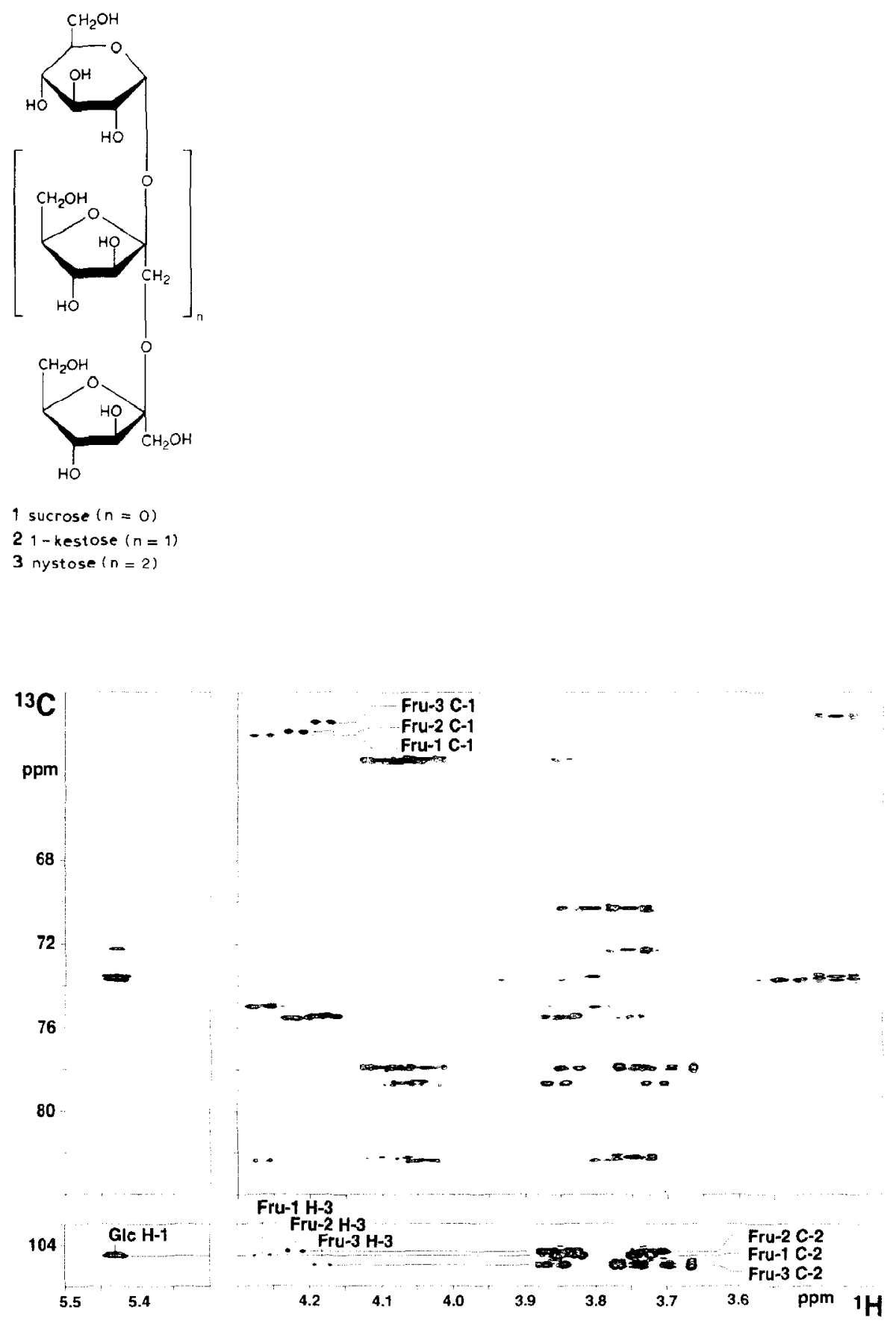

Fig. 1. $400-\mathrm{MHz}$ HMBC spectrum of a solution of nystose (3) in $\mathrm{D}_{2} \mathrm{O}$ at $27^{\circ} \mathrm{C}$. Only the spectral regions with cross-peaks are shown. In the lower part of the spectrum, the signals that are important for the sequential assignment are labeled. 
TABLE I

Assignments of the ${ }^{1} \mathrm{H}$ resonances (ppm) for $\mathbf{1 - 3}$

\begin{tabular}{|c|c|c|c|c|c|c|c|c|c|}
\hline \multirow[t]{2}{*}{ Atom } & \multicolumn{2}{|c|}{ Sucrose (1) } & \multicolumn{3}{|c|}{ 1-Kestose (2) } & \multicolumn{4}{|c|}{ Nystose (3) } \\
\hline & $\overline{\text { Glc }}$ & Fru & $\overline{\text { Glc }}$ & Fru-1 & Fru-2 & $\overline{\text { Glc }}$ & Fru-1 & Fru-2 & Fru-3 \\
\hline $\mathrm{H}-1 \mathrm{a}$ & & 3.672 & & 3.823 & 3.734 & & 3.840 & 3.859 & 3.752 \\
\hline $\mathrm{H}-1 \mathrm{~b}$ & $5.408^{a}$ & 3.672 & $5.429^{a}$ & 3.714 & 3.679 & $5.431^{a}$ & 3.741 & 3.722 & 3.685 \\
\hline $\mathrm{H}-2$ & 3.553 & & 3.539 & & & 3.537 & & & \\
\hline $\mathrm{H}-3$ & 3.755 & 4.209 & 3.749 & 4.273 & 4.186 & 3.75 & 4.268 & 4.222 & 4.182 \\
\hline $\mathrm{H}-4$ & 3.465 & 4.046 & 3.467 & 4.041 & 4.079 & 3.468 & 4.044 & 4.074 & 4.104 \\
\hline $\mathrm{H}-5$ & 3.840 & 3.884 & 3.840 & 3.868 & 3.863 & 3.83 & 3.87 & 3.86 & 3.86 \\
\hline H-6a & 3.809 & 3.819 & 3.807 & 3.813 & 3.830 & 3.81 & 3.81 & 3.82 & 3.84 \\
\hline $\mathrm{H}-6 \mathrm{~b}$ & 3.809 & 3.807 & 3.807 & 3.785 & 3.770 & 3.81 & 3.79 & 3.75 & 3.75 \\
\hline
\end{tabular}

${ }^{a} \mathrm{H}-1$ of Glc.

cross-peaks with both other sets of Fru $\mathrm{H}-1 \mathrm{a}, 1 \mathrm{~b}$ resonances $(3.722 / 3.859$ and $3.685 / 3.752 \mathrm{ppm}$ ) and, therefore, must be characterised as that of C-2 of Fru-3. The third Fru C-2 resonance at 104.35 ppm has cross-peaks with $\mathrm{H}-1 \mathrm{a}, 1 \mathrm{~b}$ of Fru-1 and another Fru $\mathrm{H}-1 \mathrm{a}, 1 \mathrm{~b}$ spin system $(3.722 / 3.859 \mathrm{ppm})$. This finding allows the identification of the resonances of $\mathrm{C}-2$ and $\mathrm{H}-1 \mathrm{a}, 1 \mathrm{~b}$ of Fru-2, and, therefore, of H-1a,1b of Fru-3. Since each Fru C-2, with known assignments, has a cross-peak with $\mathrm{H}-3$ of the same residue, the sequential assignment is complete (Table I). 'I'hese assignments enabled the complete interpretation of the ${ }^{13} \mathrm{C}$ NMR spectrum of 3 by the use of 2D HMQC and 2D HMBC experiments (Table II). The signals of $\mathrm{C}-3$ of Fru- 1 and Fru- 3 of 3 could be distinguished because the 2D HMBC shows that the $\mathrm{C}-3$ resonance of Fru-1 has the larger chemical shift. The ${ }^{1} \mathrm{H}$ and ${ }^{13} \mathrm{C}$ assignments of $\mathbf{1}$ and $\mathbf{2}$ have been checked in an analogous manner (Table I).

Two chemical-shift values were ascribed ${ }^{4}$ to the $\mathrm{H}-5$ resonance of each Fru unit of 2 , possibly suggesting the existence of two conformations, whereas only one value was assigned to H-6a,6b per Fru residue. However, from the 2D HOHAHA spectra, only one chemical shift was found for the $\mathrm{H}-5$ resonance and $\mathrm{H}-6 \mathrm{a}, 6 \mathrm{~b}$ of

TABLE II

${ }^{13} \mathrm{C}$ chemical shift data (ppm) for 1-3

\begin{tabular}{|c|c|c|c|c|c|c|c|c|c|}
\hline \multirow[t]{2}{*}{ Atom } & \multicolumn{2}{|c|}{ Sucrose (1) } & \multicolumn{3}{|c|}{ 1-Kestose (2) } & \multicolumn{4}{|c|}{ Nystose (3) } \\
\hline & Glc & Fru & Glc & Fru-1 & Fru-2 & Glc & Fru 1 & Fru-2 & Fru-3 \\
\hline $\mathrm{C}-1$ & 93.47 & 62.69 & 93.80 & 62.25 & 61.78 & 93.82 & 62.38 & 62.19 & 61.74 \\
\hline $\mathrm{C}-2$ & 72.37 & 105.02 & 72.45 & 104.57 & 105.03 & 72.48 & 104.54 & 104.35 & 104.98 \\
\hline C-3 & 73.88 & 77.77 & 73.91 & 77.99 & 77.99 & 73.92 & $78.10^{a}$ & 78.84 & $78.10^{a}$ \\
\hline C- 4 & 70.54 & 75.32 & 70.55 & 75.19 & 75.81 & 70.55 & 75.22 & 75.79 & 75.68 \\
\hline C-5 & 73.71 & 82.67 & 73.74 & 82.53 & 82.44 & 73.75 & 82.55 & 82.39 & 82.39 \\
\hline C-6 & 61.44 & 63.65 & 61.44 & 63.48 & 63.63 & 61.45 & 63.56 & 63.56 & 63.51 \\
\hline
\end{tabular}

$\bar{a}$ At higher concentrations, values of 78.16 and $78.11 \mathrm{ppm}$ were obtained for C-3 of Fru-1 and Fru-3, respectively. For other ${ }^{13} \mathrm{C}$ signals, no significant change was found. 
TABLE III

${ }^{3} J_{\mathrm{H}, \mathrm{H}}$ values $(\mathrm{Hz})$ for $\mathbf{1 - 3}$

\begin{tabular}{|c|c|c|c|c|c|c|c|c|c|}
\hline \multirow{2}{*}{$\begin{array}{l}\text { Coupling } \\
\text { constant }\end{array}$} & \multicolumn{2}{|c|}{ Sucrose (1) } & \multicolumn{3}{|c|}{ 1-Kestose (2) } & \multicolumn{4}{|c|}{ Nystose (3) } \\
\hline & Glc & Fru & Glc & Fru-1 & Fru-2 & Glc & Fru-1 & Fru-2 & Fru-3 \\
\hline$I_{1: 1,11)}$ & & n.d. ${ }^{a}$ & & -10.5 & -12.3 & & -10.8 & -10.6 & -12.2 \\
\hline$J_{1.2}$ & 3.9 & & 3.9 & & & 3.9 & & & \\
\hline$J_{2,3}$ & 9.8 & & 10.0 & & & 10.3 & & & \\
\hline$d_{3,4}$ & 10.4 & 8.7 & 9.5 & 8.7 & 8.5 & 9.0 & 8.7 & 8.4 & 8.6 \\
\hline$J_{4.5}$ & 10.0 & 8.6 & 9.8 & 8.3 & 8.1 & 10.0 & 8.6 & 8.1 & 7.9 \\
\hline$J_{5, \mathrm{ha}}$ & $3.3^{b}$ & 2.9 & $3.3^{h}$ & 3.4 & 3.0 & $3^{k}$ & 3 & 3 & 3 \\
\hline$j_{5,6 \mathrm{~b}}$ & $3.3^{h}$ & 7.4 & $3.3^{b}$ & 7.2 & 7.1 & $3^{k}$ & 7 & 7 & 7 \\
\hline
\end{tabular}

the Fru gave rise to two distinct resonances. This result points to the existence of only one average conformation on the NMR time scale.

Previous ${ }^{1.3} \mathrm{C}$ NMR investigations ${ }^{5}$ of $\mathbf{2}$ and $\mathbf{3}$ were based on a comparison with data for related compounds. The present data show that the assignments ${ }^{5}$ of the resonances of $\mathrm{C}-2$ of Fru-1 and Fru-3 of 3 have to be interchanged. Similar interchanges have been found ${ }^{4}$ for 2 . Furthermore, the assignment ${ }^{5}$ of the signals C-1 of Fru-1, C-1,4 of Fru-2, and C-4 of Fru-3 of 3 have now been corrected.

In order to obtain reliable ${ }^{3} J_{\mathrm{H}, \mathrm{H}}$ values for $\mathbf{1}-\mathbf{3}$, which are useful for conformational analysis, $600-\mathrm{MHz}{ }^{1} \mathrm{H}$ NMR spectra have been simulated. The chemical shifts and coupling constants (Tables I and III) were optimised by an iterative process. Because of the overlapping of signals in the 1D spectrum of 3 , the parameters for $\mathrm{H}-5,6 \mathrm{a}, 6 \mathrm{~b}$, which were obtained from $2 \mathrm{D}$ spectra, could not be determined with the same accuracy as for the other protons. The agreement between the observed and the theoretical spectra is good.

Thus, the chemical shifts of all of the ${ }^{1} \mathrm{H}$ and ${ }^{13} \mathrm{C}$ resonances and all the ${ }^{3} J_{H .11}$ values for 1-3 have been determined. For $\mathbf{2}$ and 3, this is the first report of a complete interpretation of the ${ }^{1} \mathrm{H}$ NMR spectrum.

\section{EXPERIMENTAL}

Materials. - Sucrose (1) was converted into 1-kestose (2) and nystose (3) enzymically $^{18}$. The products were isolated and purified from the mixture ${ }^{19}$, to yield $1.1 \mathrm{~g}$ of 2 and $0.48 \mathrm{~g}$ of $\mathbf{3}$.

NMR spectroscopy.--Solutions in $\mathrm{D}_{2} \mathrm{O}(99.9$ atom $\% \mathrm{D})$ were lyophilised and each residue was dissolved in $0.5 \mathrm{~mL}$ of $\mathrm{D}_{2} \mathrm{O}(99.96$ atom $\% \mathrm{D})$. The 2D DQF-COSY spectrum of nystose and all $2 \mathrm{D} \mathrm{HMQC}^{20}$ and $2 \mathrm{D} \mathrm{HMBC}^{21}$ experiments were recorded with 75-mg samples, the other NMR experiments with 5-mg samples. The probe temperature was kept at $27^{\circ} \mathrm{C}$. Chemical shifts are expressed in ppm downfield from the signal for 4,4-dimethyl-4-silapentane-1-sulfonate (DSS), but 
were actually measured relative to that of internal acetone $\left(2.225 \mathrm{ppm}\right.$ for ${ }^{1} \mathrm{H}$, and $31.55 \mathrm{ppm}$ for ${ }^{13} \mathrm{C}$ ). The spectra were obtained with a Bruker AMX-400-WB (ATO-DLO/RIKILT-DLO, Wageningen), AM-500 (Bijvoet Center, Department of NMR Spectroscopy, Utrecht University), or AM-600 (NSR centre, Nijmegen University) spectrometer. Processing of NMR data was performed on a $\mu$ VAX/VMS cluster with the TRITON 2D-3D-NMR software package (R. Boelens and R. Kaptein, Bijvoet Center, Department of NMR Spectroscopy, Utrecht University).

The 1D spectra of 1-3 were obtained at $600 \mathrm{MHz}\left({ }^{1} \mathrm{H}\right)$ and $100 \mathrm{MHz}\left({ }^{13} \mathrm{C}\right) .2 \mathrm{D}$ HOHAHA spectra of 1-3 were obtained at $600 \mathrm{MHz}$ by acquisition of 512 experiments of $2 \mathrm{~K}$ data points. For each compound, 16- and 110-ms MLEV-17 spin-lock pulse sequences ${ }^{22}$ were used (short and long mixing times, respectively). A 2D DQF-COSY spectrum of 3 was obtained at $400 \mathrm{MHz}$, using $2 \mathrm{~K}$ data points in the $\omega_{2}$ dimension and $1 \mathrm{~K}$ data points in the $\omega_{1}$ dimension. A $2 \mathrm{D}$ HMQC spectrum ${ }^{20}$ of 3 and $2 \mathrm{D} \mathrm{HMBC}$ spectra $^{21}$ of 2 and 3 were recorded at $400 \mathrm{MHz}$ with a time domain of $2 \mathrm{~K}$ data points. For the $2 \mathrm{D}$ HMQC spectrum, 1024 experiments of 60 scans each were recorded, and, for the 2D HMBC spectra of 2 and 3, 2048 experiments of 100 and 160 scans, respectively, were acquired. Magnitude calculation was performed for the 2D HMBC experiments in the $\omega_{2}$ dimension, after Fourier transformation.

Simulation of ${ }^{1} H$ NMR spectra.--Subspectra arising from each spin system of 1-3 were simulated by a local version of a LAOCOON program ${ }^{23}$ on a $\mu \mathrm{VAX} / \mathrm{VMS}$ cluster. In order to obtain complete ${ }^{1} \mathrm{H}$ NMR spectra of each compound, the simulated subspectra for the constituent spinsystems were scaled and added.

\section{ACKNOWLEDGMENTS}

This work was supported by the Netherlands Foundation for Chemical Research (SON) with financial aid of the Netherlands Foundation of Scientific Research (NWO). The authors thank Dr. A.S. Ponstein (ATO-DLO) for the preparation of $\mathbf{2}$ and $\mathbf{3}$.

\section{REFERENCES}

1 R.H.F. Beck and W. Praznik, Staerke, 38 (1986) 391-394.

2 A. Fuchs, Staerke, 39 (1987) 335-343.

3 D.D. McIntyre and H.J. Vogel, Staerke, 43 (1991) 69-76.

4 T.M. Calub, A.L. Waterhouse, and N.J. Chatterton, Carbohydr. Res., 199 (1990) 11-17.

5 H.C. Jarrell, T.F. Conway, P. Moyna, and I.C.P. Smith, Carbohydr. Res, 76 (1979) 45-57.

6 A. De Bruyn, J. van Beeumen, M. Anteunis, and G. Verhegge, Bull. Soc. Chim. Belg., 84 (1975) $799-811$.

7 A.J. Jones, P. Hanisch, and A.K. McPhail, Aust. J. Chem., 32 (1979) 2763-2/66.

8 W.W. Binkley, D. Horton, N.S. Bhacca, and J.D. Wander, Carbohydr. Res., 23 (1972) 301-306.

9 K. Bock and R.U. Lemieux, Carbohydr. Res., 100 (1982) 63-74. 
10 C.H. du Penhoat, A. Imberty, N. Roques, V. Michon, J. Mentech, G. Descotes, and S. Pérez, J. Am. Chem. Soc., 113 (1991) 3720-3727.

11 A.L. Waterhouse, T.M. Calub, and A.D. French., Carbohydr. Res., 217 (1991) $29-42$.

12 B. Mulloy, T.A. Frenkiel, and D.B. Davies, Carbohydr. Res., 184 (1988) 39-46.

13 A. Heyraud, M. Rinaudo, and F.R. Taravel, Cartohydr. Res., 128 (1983) 311-320.

14 A. De Bruyn and J. Van Loo, Carbohydr. Res., 211 (1991) 131-136.

15 M. Manley-Harris and G.N. Richards, Carbohydr. Res., 219 (1991) 101-113.

16 D.G. Streefkerk and C.P.J. Glaudemans, Biochemistry, 16 (1977) 3760-3765.

17 N. Shiomi and S. Onodera, Agric. Biol. Chem., 54 (1990) 215-216.

18 H. Hidaka, M. Hirayama, and N. Sumi, Agric. Biol. Chem., 52 (1988) 1181-1187.

19 P.C. Ivin and M.L. Clarcke, J. Chromatogr., 408 (1987) 393-398.

20 L. Müller, J. Am. Chem. Soc., 101 (1979) 4481-4484.

21 A. Bax and M.F. Summers, J. Am. Chem. Soc, 108 (1986) $2093-2094$.

22 D.G. Davis and A. Bax, J. Am. Chem. Soc, 107 (1985) 2820-2821.

23 S. Castellano and A.A. Bothner-By, J. Chem. Phys., 41 (1964) 3863-3869. 